\title{
Los mapas antiguos como fuente de información Aportes para su descripción documental
}

Graciela Bienes

Universidad de Buenos Aires. Facultad de Filosofía y Letras. Departamento de Bibliotecología y Ciencia de la Información | gbienes@filo.uba.ar / https://orcid.org/oooo-0002-5065-055X

\begin{abstract}
Resumen
Para las bibliotecas, los mapas antiguos constituyen, desde el punto de vista del procesamiento técnico, una de las tipologías documentales más complejas. Por su doble naturaleza, cartográfica e histórica, por la variedad de las características iconográficas y simbólicas que presentan y por los elementos artísticos empleados en su ornamentación, su análisis documental no es sencillo. Esta tarea muchas veces se torna aún más trabajosa por la ausencia de datos -ya sea debido a que no fueron incorporados en el momento de creación de la obra o a una posterior pérdida de soporte- y por las lenguas extranjeras o arcaicas en la que están expresados los rótulos y textos que incluyen. El objetivo de este trabajo es presentar algunas de las características que, con mayor frecuencia, aparecen en estos documentos para contribuir con la elaboración de registros que contengan detalles precisos y exhaustivos. Una descripción catalográfica con mayor nivel de detalle brindará a los investigadores de diferentes disciplinas, un conocimiento más preciso de los fondos cartográficos que consulten.
\end{abstract}

\section{Old maps as information source: contributions for their description}

\begin{abstract}
For libraries, old maps are, from the point of view of technical processing, one of the most complex document types. Due to its double nature, cartographical and historical, due to the variety of iconographic and symbolic characteristics that they present and the artistic elements used in their ornamentation, their analysis is not simple. This task is often made even more difficult because the lack of data -either because they were not incorporated at the time of creation of the work or a later loss of physical medium- and their texts are expressed in foreign or archaic languages. The purpose of this work is to present some of the characteristics that appear more often in these
\end{abstract}

\section{Palabras clave}

Mapa antiguo Cartografía Iconografía geográfica Descripción documental Semiología cartográfica
Keywords

Old map Cartography Geographical iconography Documentary description Cartographical semiology 
1. El presente artículo se basa en el proyecto de investigación

La cartografía antigua como fuente de información: aportes para un modelo de descripción documental, correspondiente a la Línea de Investigación Histórica del Instituto de Investigaciones Bibliotecológicas (INIBI) de la Facultad de Filosofía y Letras de la Universidad de Buenos Aires, dirigida por Alejandro E. Parada, con la coordinación de Beatriz C. Valinoti. Una ponencia sobre ese trabajo fue presentada en la I Jornada de Investigación INIBI 2015.

2. "Podemos pues decir, como primera hipótesis, que la carta además de organizar simbólicamente las relaciones entre los objetos situados en un espacio geográfico (a través de la visión cenital), tiene un origen mágicoreligioso, y no técnico instrumental. El pueblo Camuno y la antigua Liguria no poseían la noción de la geometría euclidiana, sin embargo, realizaron representaciones que hoy interpretamos como cartas de su territorio. Pero este mapa debía servir como elemento sacro o ritual y, posiblemente, aunque no seguro, como instrumento para fijar límites fundiarios y territorios de caza. Para el Monte Bego, la versión que da Biknell (1913) aparece aún plausible: como representación del territorio cual "copia" bien visible y a disposición de la divinidad, de modo de proteger de cualquier suerte al territorio "verdadero" de su eventual ira" (Torricelli, Gian Paolo, 2000: 11).

3. “El cartógrafo tiene horror al vacío. Los mapas más antiguos, como los mapamundis T-O, ofrecen a la interpretación su misma compacidad. Desde el día en que la Cristiandad se puso en marcha para conquistar la tierra, quiso reconocer lo que se le seguía escapando: las terrae incognita como signos de interrogación sobre los mapas de los siglos XIII, $\mathrm{XIV}, \mathrm{XV}$, incluso del XVI. Aunque hay que poder hablar de ellas.

El cartógrafo concentra en estos espacios inciertos lo que le sugiere su fantasía o su ciencia: imágenes monstruosas, inscripciones ("Aquí solo se extienden áridas arenas" ...) o el simple reticulado de los rumbos, y la representación de los vientos. El vacío, en efecto, es absurdo, ni más ni menos." (Zumthor, Paul, 1994: 329). documents to help elaborate records that contain precise and exhaustive details. A more detailed documentary description will provide researchers of different disciplines with a more precise knowledge of the cartographical funds they consult.

Artículo recibido: 01-04-2019. Aceptado: 22-05-2019

\section{Introducción ${ }^{1}$}

El mapa es uno de los modelos de representación y de expresión más antiguo que se conoce. Es anterior a la escritura y a la notación matemática, porque estos dos sistemas requieren un mayor grado de abstracción simbólica. El mapa es, además, una manifestación casi universal, la mayoría de las sociedades, aun las más primitivas, los han utilizado como instrumento para representar el espacio en el que habitaron.

El hombre trató, desde siempre, de reproducir su entorno. Lo delineó en las paredes de una gruta, sobre huesos de animales, piedras o maderas. A esos primeros mapas, en el sentido más amplio, se les atribuye un valor mágico-religioso²: el ofrecimiento a la divinidad de una imagen simbólica del territorio para que este quedara protegido ante la posible ira del dios que se manifestaría a través de fenómenos climáticos o geológicos. Estos pueblos, anteriores a formas de organización urbana, también hicieron uso del mapa utilitario que servía para transmitir, de generación en generación, información vital: el trazado de recorridos de caza, la ubicación de las fuentes de agua, la delimitación de las zonas de peligro.

Con las primeras civilizaciones estables las funciones del mapa instrumental se amplían, sirven para determinar distancias, medir tierras, registrar los territorios conquistados, establecer límites, localizar posiciones enemigas durante los enfrentamientos. Pero más allá de su carácter utilitario, la cartografía, al sustituir el espacio real por el espacio analógico (Lois, 2015) le permitió al hombre adquirir un dominio intelectual sobre un mundo, a la vez que tomaba conciencia de que las zonas desconocidas eran mucho más extensas que aquellas que le eran familiares.

En la antigüedad clásica, los griegos a partir de su interés por los conocimientos matemáticos y astronómicos establecieron principios fundamentales para la representación científica de la superficie terrestre: el concepto de esfericidad de la Tierra y la medida (muy aproximada) de su diámetro, el sistema de latitudes y longitudes y las primeras proyecciones. A diferencia de los griegos, para los romanos la cartografía era un instrumento práctico que utilizaron con fines militares, administrativos y comerciales.

Con la caída del Imperio Romano, la cartografía occidental, basada en una concepción teocrática del mundo, perdió exactitud y se convirtió en una representación simbólica de carácter religioso. Recién a fines del siglo XIII aparece un nuevo tipo de mapas: los portulanos. Los portulanos eran cartas náuticas diseñadas para navegar por el Mar Mediterráneo en las que se describían las costas con sus puertos y accidentes geográficos, el sistema de rosas de los vientos y la red de rumbos (líneas que debía seguir la nave).

A mediados del siglo XVI se inicia la cartografía ornamental. Ante la ausencia de conocimientos geográficos precisos sobre algunas regiones, los cartógrafos incluían viñetas, figuras fantásticas o mitológicas y elementos decorativos 3 . Antes de finalizar ese mismo siglo, los descubrimientos geográficos, la expansión territorial de las potencias europeas, el desarrollo de instrumentos de medición, los adelantos en las técnicas de navegación, dan lugar a una cartografía cada vez más exacta y minuciosa. Los 
nuevos espacios que se descubrían se proyectaban por escrito con la aplicación de reglas cada vez más complejas. Al mismo tiempo, la imprenta y el avance de las técnicas de grabado hicieron posible la publicación de gran cantidad de copias de mapas.

Durante el siglo XVIII, se realizan trabajos cartográficos más formales con fines de investigación. A partir del siglo XIX se crearon los distintos servicios cartográficos estatales que sentaron las bases de la cartografía moderna de Estado. Se realizaron levantamientos topográficos y se inició la publicación de cartas topográficas de gran escala. Contar con un mapa topográfico estatal como instrumento militar, fiscal y territorial era considerado por los gobiernos un alto objetivo estratégico (Carrascal Simón y Gil Tort, 2007).

A medida que la cartografía se fue transformando en una disciplina científica, los mapas fueron considerados productos neutrales, técnicos y transparentes. Su lectura tradicional suponía que el objetivo principal de todo mapa era lograr una representación fiel de la realidad (Torricelli, 2000; Lois, 2000).

A partir de los años ochenta del siglo pasado, un grupo de geógrafos y cartógrafos, entre los que se destaca John Brian Harley, comienza a emplear principios de la semiología para analizar los materiales cartográficos. Harley advierte sobre la dimensión sociopolítica de los mapas e invita a descubrir el contenido ideológico presente en cada uno de ellos. Sostiene la necesidad de un cambio epistemológico en la forma de interpretar la naturaleza de la cartografía.

Harley (2005) plantea que los mapas son textos de características similares a otros sistemas de signos no verbales (cuadros, cine, grabados, etc.). Emplean un lenguaje gráfico, regido por reglas no gramaticales, que se debe decodificar para ser interpretado. Para este autor el estudio de los mapas tiene puntos de contacto con el del libro. Tanto libros como mapas despliegan su función textual y son objeto de interpretación, análisis histórico y control bibliográfico. Ambos son productos no solo de quienes intervienen directamente en su elaboración (autores, editores, etc.) sino también de los valores culturales imperantes en cada sociedad y en cada época.

El mapa no es un mero conjunto de conocimientos geográficos y matemáticos, procedimientos técnicos y práctica gráfica. La cartografía es una forma de interpretación, de traducción del mundo real y cualquier forma de interpretación dista mucho de ser neutra u objetiva. La producción y el uso de los mapas representan ideologías culturales y han sido útiles como herramientas de dominación social y territorial. ${ }^{4}$

\section{La descripción bibliográfica del material cartográfico antiguo en las bibliotecas}

Un rasgo distintivo de las mapotecas es su dependencia de una institución u organización superior: archivos, bibliotecas, museos, institutos geográficos y cartográficos e instituciones militares (Galera i Monegal, 2001).

Entre los archivos y las bibliotecas existen diferencias en cuanto al origen y compilación de la documentación cartográfica que conservan. En un archivo los documentos cartográficos se caracterizan por su relación con la entidad productora y forman parte de expedientes gestionados por diversas cuestiones, suelen ser únicos, originales y, en muchos casos, no son impresos sino manuscritos (García Ruipérez, 2010).

Las bibliotecas, en cambio, almacenan colecciones cartográficas que se han acumulado artificialmente, generalmente sin mantener su origen orgánico ni mostrar la actividad
4. “En el sentido de poder más común en la cartografía es el del poder externo a los mapas y el mapeo. Este sirve para relacionar a los mapas con los centros de poder político. El poder se ejerce sobre la cartografía. Detrás de la mayoría de los cartógrafos está una persona que encarga un mapa; en numerosos casos, quienes producen los textos cartográficos respondían a necesidades externas. Por otra parte, el poder también se ejerce con la cartografía. Monarcas, ministros, instituciones estatales, la Iglesia, todos han iniciado programas de mapeo para fines particulares. En la sociedad occidental moderna, los mapas rápidamente se volvieron cruciales para la conservación del poder del Estado (para sus fronteras, comercio, administración interna, contro de población y fuerza militar)." (Harley, John Bryan, 2005: 203). 
del ente productor. Las que reúnen fondos cartográficos importantes suelen ser las universitarias y las nacionales (Jiménez Pelayo, 1996). En estas instituciones el tratamiento y catalogación de los mapas es relativamente reciente. Como antecedente se puede mencionar el primer catálogo temático de la Real Biblioteca de España (que en 1836 pasó a ser Biblioteca Nacional), escrito en 1729 por el bibliotecario Juan de Iriarte y Cisneros. Este catálogo denominado Regia Matritensis Bibliotheca Geographica et Cronologica, está referido a los fondos geográficos y describe más de setecientos documentos (Líter Mayayo, 2007). Las bibliotecas nacionales iniciaron la descripción documental de sus colecciones de mapas en el siglo XIX. Lo mismo ocurrió con los fondos cartográficos de las bibliotecas universitarias. En 1831 apareció, en forma de libro impreso, el Catalogue of the Maps and Charts in the Library of Harvard University. Cambridge, Massachusetts.

Uno de los primeros artículos que describía procedimientos para la catalogación de mapas fue publicado en 1902 por Thomas Letts en la revista Library Journal (Líter Mayayo, 2011).

En nuestro país, la Biblioteca Pública de Buenos Aires incluyó mapas en sus fondos generales desde su creación en 1810. Pero recién en la década de 1940, ya como Biblioteca Nacional y bajo directivas de su Secretario General, Manuel Selva, se inició la organización de esos documentos según normas bibliotecológicas y se les asignó un espacio de guarda y consulta separado del resto de la colección. La actual Mapoteca de la Biblioteca Nacional lleva hoy el nombre de Selva, quien, además, publicó en 1941 la Guía para la Organización, Fichado y Catalogación de Mapotecas (Funes, 2014).

Las características referidas a la procedencia y ordenación de los documentos cartográficos, condicionan la descripción de los mismos. En los archivos, con frecuencia se emplean modelos de datos generales que permiten la descripción del material cartográfico a un nivel muy somero (por ejemplo, la norma ISAD(G) - General International Standard Archival Description - desarrollada por el Consejo de Archivos) (Sainz Guerra, 2008).

Las bibliotecas por su parte han empleado tradicionalmente las especificaciones de dos normas de aplicación internacional que hacen posible un mayor nivel de detalle: AACR2 (Anglo-American Cataloguing Rules) y ISBD (CM) (International Standard Bibliographic Description for Cartographic Materials). Esta última fue reemplazada en el año 2007 por la edición consolidada de las ISBD que incluyó a las que se aplicaban a materiales especiales (Hazrum, 2008; Gorostiaga y Mateo-Ré, 2008; Machado Lorenzo, 2009; Líter Mayayo, 2011).

Las ISBD y AACR2, que fueron creadas para los materiales impresos y los catálogos en ficha, se adaptaron a las tecnologías de las últimas décadas del siglo XX. Pero el aumento notable de la producción y circulación de la información electrónica demostró, en poco tiempo, que era necesaria una profunda actualización de la normativa catalográfica y que la misma, además de responder a la realidad tecnológica, debería mantener el alcance internacional (Picco y Ortiz Repiso, 2012). En el año 2010, fueron presentadas las directrices RDA (Resource Description and Access) que, después de un período de evaluación, fueron adoptadas progresivamente por importantes bibliotecas de América del Norte y Europa, a las que se sumaron instituciones de Australia y Asia.

En este artículo, por razones que se explicarán más adelante, se seguirán los lineamientos de los estándares ISBD (CM) y AACR2. En la descripción catalográfica de los mapas y planos conservados en bibliotecas, según lo que establecen las normas mencionadas, se utilizan áreas comunes con las de otras publicaciones 
impresas (áreas de título y mención de responsabilidad, de edición, de publicación, de descripción física, de notas) y se agregan otras específicas para esos documentos (área de datos matemáticos).

Para la catalogación de mapas impresos antiguos las herramientas que brindan estos estándares resultan insuficientes porque la naturaleza de este material y su riqueza gráfica requieren la aplicación de criterios catalográficos más complejos. El capítulo 3 Materiales cartográficos de las AACR2, expresa que sus reglas "No cubren en detalle la descripción de materiales cartográficos manuscritos o antiguos..." (AACR2, 2004:3-3).

Es importante tener en cuenta que los mapas antiguos constituyen una fuente de información para geógrafos y cartógrafos, pero también para especialistas de las más diversas disciplinas: semiólogos, historiadores, antropólogos, diseñadores gráficos, historiadores del arte y de la ciencia, museólogos, bibliotecarios y conservadores, entre otros. Cada uno de estos colectivos analiza el mapa antiguo desde diferentes perspectivas: como discurso, como dispositivo de comunicación, como elemento de apropiación del espacio, cómo medio para comprender la organización social y la actividad humana, como instrumento para determinar la capacidad artística en el momento en que fue creado, como herramienta para conocer el estado del conocimiento geográfico y del desarrollo tecnológico de la época o como representación del paisaje del pasado.

No son numerosos los trabajos sobre la descripción documental de la cartografía antigua. Jiménez Pelayo (1996) y Machado Lorenzo (2009) ponen de manifiesto los problemas que presenta el análisis documental de este tipo de material y proponen la elaboración de una metodología para lograr una descripción más adecuada. Ambos autores remarcan la importancia del área de notas para reflejar los aspectos externos e internos más relevantes.

En Argentina los escasos catálogos de mapas antiguos de bibliotecas que se pueden consultar en línea, muestran registros de nivel elemental, con datos mínimos. Sería beneficioso contar con una normativa específica que permita elaborar registros bibliográficos de este material con un mayor grado de detalle para que los usuarios puedan encontrar información abundante y precisa sobre el mismo.

\section{Elementos para la caracterización de los mapas antiguos}

En primer lugar, es preciso señalar que bajo la denominación cartografía antigua se consideran los documentos anteriores al año 1901 y que este trabajo se ocupará de la producción cartográfica impresa.

El análisis del mapa antiguo requiere la comprensión del contexto histórico, cultural y científico en el que fue elaborado el documento. En este tipo de material, el entorno de producción, la concepción estética, los recursos retóricos y los símbolos elegidos para las representaciones, son generalmente más importantes que los datos matemáticos que incluye.

Para describir la información contenida en el material cartográfico, tanto las ISBD (CM) como las AACR2 (que dedican el capítulo 3 a los documentos cartográficos), emplean una división en áreas bibliográficas.

Las áreas que se emplean en el procesamiento de los materiales cartográficos antiguos son: 
1. Área de título y mención de responsabilidad.

2. Área de edición.

3. Área de datos matemáticos.

4. Área de publicación, impresión, distribución, etc.

5. Área de descripción física.

6. Área de notas.

Las AACR2 indican que la fuente principal de información para la primera área es el mapa en sí mismo y su envase, si lo tuviera, es decir que la información bibliográfica para describir un mapa antiguo se debe extraer del propio documento o de la cubierta o sobre que lo contiene. Para las áreas de edición, datos matemáticos, publicación y serie los datos se deben obtener de la fuente principal de información y del material impreso complementario. Para las áreas de descripción física y notas se puede utilizar cualquier fuente. La información que sea tomada de cualquier otra fuente que no sean las prescriptas para cada área, debe encerrarse entre corchetes.

En este trabajo se intentará armonizar las normas internacionales de catalogación del material cartográfico moderno con las necesidades de descripción de los documentos antiguos. Por lo tanto, solo se hará una propuesta para incorporar los elementos de descripción necesarios para caracterizar e individualizar estos últimos. No se analizará la forma de trascripción de esos datos como así tampoco cuestiones referidas a puntuación, espaciado, uso de mayúsculas, signos diacríticos, etc., que se detallan en los estándares mencionados.

A continuación, se considerarán las formas más comunes de presentación de la información en los mapas antiguos y las dificultades que se pueden originar en cada área de descripción. Es importante señalar que, además del problema relacionado con la disposición de los datos- característica de la naturaleza de estos materiales-, suelen encontrarse otros, similares a los que presentan los documentos antiguos en general: elementos inexistentes, textos y rótulos en diferentes lenguas e información perdida por faltante del soporte.

\section{Título y mención de responsabilidad}

a) Título

El título propiamente dicho es el elemento que identifica el contenido de un documento cartográfico. En el material cartográfico antiguo con frecuencia aparecen varios títulos, circunstancia que muchas veces hace difícil una elección adecuada del mismo.

Si el documento presenta títulos en dos o más lenguas, se debe transcribir como propio el que coincide con la lengua del contenido de la obra.

Si todos los títulos aparecen en la misma lengua se debe considerar la secuencia o disposición de los mismos en el documento. Pero esto no resulta simple porque en los mapas la información no se expone de manera secuencial sino simultánea y dispersa. Previendo esta situación la norma agrega que si no se puede tomar una decisión se debe elegir el título más general o de mayor alcance.

Frente a estos inconvenientes, Jiménez Pelayo (1996: 134) recomienda las pautas elaboradas en 1981 por el Anglo-American Cataloging Committee for Cartographic Materials (organismo compuesto por bibliotecas nacionales y asociaciones cartográficas de Estados Unidos, Reino Unido, Canadá, Australia y Nueva Zelanda cuyos representantes son reconocidos expertos en el control bibliográfico de materiales cartográficos): 
1. Se debe elegir como título propio el que exprese con más claridad tanto el área como la materia cubierta por el documento.

2. Cuando esto no sea posible, se debe escoger el título con el siguiente orden de preferencia:

» a) un título situado dentro de la línea que delimita el borde del documento.

" b) un título situado en el recto del documento fuera del borde.

" c) un título del panel (por título del panel se entiende aquel título que aparece fuera de la hoja propiamente dicha cuando ésta se pliega conforme a un plan determinado; puede estar situado tanto en el recto como en el verso del documento).

d) un título situado en el verso del documento.

» e) un título situado en la cubierta, envase, etc.

En los mapas antiguos con frecuencia los títulos son extensos. Si bien cabe la posibilidad de abreviar un título demasiado largo, siempre que no se pierda información, es poco aconsejable hacerlo porque en muchas ocasiones las diferencias mínimas en un título son las que hacen posible reconocer distintas ediciones del mismo documento.

Cuando un mapa no presenta título será necesario redactar un título facticio que refleje su contenido lo más fielmente posible. Este título facticio deberá redactarse en la misma lengua del documento y estará formado por el nombre del área geográfica representada.

\section{b) Mención de responsabilidad}

El mapa antiguo es el resultado de un trabajo colectivo, aunque cada etapa de ese trabajo solía realizarse en forma individual, de manera que es posible, en muchos casos, atribuir la responsabilidad de cada fase de la producción cartográfica a una persona en particular. No obstante, en muchas ocasiones esta identificación se torna compleja. Por ejemplo, durante los siglos XVI y XVII, el perfil del cartógrafo o del geógrafo no aparece claramente definido. El cartógrafo podía ser al mismo tiempo artesano, artista (muchos de ellos eran eximios grabadores), matemático, investigador, empresario editor y funcionario de la corona.

Las menciones de responsabilidad que aparezcan de manera destacada en el documento se deben transcribir textualmente.

Los términos y/o abreviaturas que se emplean para citar al responsable del trabajo cartográfico, tanto en el aspecto intelectual como artístico, en un mapa antiguo son numerosos. Estas menciones y sus abreviaturas en latín se pueden reunir en dos grupos:

I. Autor, cartógrafo, geógrafo, delineante o dibujante, sus autorías, en caso de especificarse, se señalaban bajo las expresiones latinas: auctore, auct., delineavit, del., desinavit, descripsit, descrip., effigiavit, formis, invenit, inv., y sus equivalentes en lenguas vernáculas.

II. Grabador, su trabajo se acreditaba con las fórmulas: sculpsit, sculp., sc., fecit, fec., caelavit, incidit, scripsit (para la letra) o grabó, gravée, etc.

En lengua vernácula, pueden aparecer sustantivos o frases que se refieren a la tarea o función desempeñada por una o más personas, como: agrimensor, levantado por o levée par, etc.

Por la importancia que adquiere la autoría en la identificación del material cartográfico antiguo, es conveniente no omitir ninguna mención de responsabilidad. Los 
responsables principales se deben consignar en el Área 1 y todos los secundarios (los que no figuran en el documento de forma destacada o a quienes -a través de otras fuentes- se les atribuye participación en la obra), en una nota, siguiendo el orden secuencial del documento o, a falta de este, el que se considere más lógico o con más sentido. También se deben conservar las expresiones que denotan origen, tratamiento, profesión, dignidad o cargo porque brindan información que sirve para la individualización del documento, especialmente cuando se estudian las obras de un mismo autor.

En el caso de hojas sueltas de atlas, en las que no figura el nombre del responsable porque aparece en la portada de la obra, el mismo debe indicarse en una nota. Si en el documento cartográfico no se menciona la responsabilidad, es necesario realizar un trabajo de investigación para indagar sobre la identidad del posible autor. Hallado el nombre del mismo se registrará en una nota junto con la fuente de información consultada.

\section{Edición}

En los documentos cartográficos antiguos no siempre se indican la edición y la responsabilidad de la misma. Si estos datos se encuentran, se aconseja mencionarlos como aparecen en el ejemplar.

\section{Datos matemáticos}

En esta área se incluyen los elementos específicos de los materiales cartográficos. En los mapas antiguos no es frecuente que aparezcan menciones sobre datos matemáticos, a excepción de la escala.

La escala cartográfica es la relación que existe entre las medidas de la representación gráfica en el mapa y sus correspondientes en la superficie real. Como es una correspondencia matemática, en los mapas modernos la escala se indica como una fracción en la que el numerador es la unidad de medida empleada en el mapa y el denominador el número de esas unidades en el terreno. En los mapas antiguos, anteriores a la utilización del Sistema Métrico Decimal, la relación se establecía entre dos magnitudes con diferentes unidades de medida y se representaba en forma gráfica. La conversión de las escalas de esos documentos al sistema actual es un proceso muy complicado porque las medidas que se empleaban eran muy variadas y hoy están en desuso.

5. Para equivalencias de medidas antiguas en centímetros se pueden consultar las tablas incluidas en: Líter Mayayo, Carmen y Carmen García Calatayud (1999: 295-300).
Un ejemplo de ese tipo de escala es la de los portulanos. Estas cartas de navegación llevaban, para calcular las distancias entre los distintos puertos del mar Mediterráneo, una escala en leguas, representada como una recta, tronco o barra, dividida en segmentos iguales, que se denominaba "tronco de leguas". Si bien el valor estaba expresado en leguas, en los mapas portugueses, españoles, italianos, holandeses y franceses el valor atribuido a la legua variaba.

Los mapas antiguos también suelen presentar márgenes graduados. Estas reglas son escalas con divisiones en grados y minutos, paralelas al marco del mapa, que establecen en sentido vertical la latitud y en sentido horizontal la longitud. 


\section{Publicación, impresión y distribución}

En esta área se debe registrar la información relacionada con el lugar, nombre y fecha de todas las actividades referidas a la publicación, impresión y distribución del documento.

Las AACR2 indican que para los detalles de publicación correspondientes a los materiales cartográficos antiguos se deben seguir las normas establecidas para las monografías impresas anteriores a 1801.

\section{a) Lugar}

El lugar de publicación debe transcribirse tal como aparece en el documento y si se menciona más de un lugar es conveniente citar todos en el orden en el que se encuentran. Si el lugar o los lugares tienen un nombre moderno, debe agregarse entre corchetes para facilitar su identificación.

Es conveniente señalar a continuación del nombre del lugar, el del país, estado, provincia, etc., para caracterizarlo con precisión o para distinguirlo de otros iguales o similares. Siempre es importante registrar el lugar, provincia y país. Si no figura en el documento, se debe indicar el lugar probable entre corchetes y con un signo de interrogación.

\section{b) Nombre}

El editor o librero guarda relación con el lugar de publicación, por esta razón su nombre se debe registrar a continuación de este último.

En épocas pasadas las tareas del editor, del impresor y del librero no siempre estaban bien delimitadas. En muchas ocasiones una misma persona desempeñaba dos de esas ocupaciones o, incluso, las tres. Como se señaló en mención de responsabilidad, los nombres del editor, impresor, etc., también suelen estar precedidos por gran variedad de fórmulas de entrada. Muchas veces estas expresiones son utilizadas indistintamente tanto para el editor como para el impresor o para el librero, situación que hace difícil identificar la función desempeñada. Algunas de estas fórmulas son:

I. Impresor: en la imprenta, imprimé (en lengua vernácula); ex typographia, ex typis, ex tipog, ex tip., excudebat, excudit, excussit, chalcographus (en latín).

II. Editor o librero: en casa de, chez, en la librería, a costa, met privilegie (en lengua vernácula); apud, in aedibus, sumptibus (en latín).

III. Fórmulas ambiguas: por/par + nombre propio (en lengua vernácula); ex/in/en la + officina... (en latín).

Si se pueden distinguir claramente los nombres del editor y del impresor, se debe registrar el lugar de edición y el nombre del editor y el lugar de impresión y el nombre del impresor.

\section{c) Fecha}

La fecha de publicación o de impresión debe registrarse como aparece en el documento. Si no corresponde al calendario gregoriano se agregará la fecha en la cronología moderna. Los números romanos que indican el año se cambiarán por número arábigos. 
Si en la obra no aparece ninguna fecha de publicación, impresión, etc., se proporcionará una fecha aproximada entre corchetes según la siguiente tabla:

\section{Ejemplo}

\begin{tabular}{ll}
\hline Uno u otro año & {$[163501636]$} \\
Fecha probable & {$[1675 ?]$} \\
Fechas con menos de 20 años de diferencia & {$[$ entre 1625 y 1640] } \\
Fecha aproximada & {$[$ ca.1598] } \\
Década segura & {$[164-]$} \\
Década probable & {$[164-?]$} \\
Siglo seguro & {$[15--]$} \\
Siglo probable & {$[15--?]$} \\
"no después de" / "no antes de" & {$[$ no después de 1684] }
\end{tabular}

\section{Descripción física}

En esta área se debe detallar la apariencia exterior del documento cartográfico.

\section{a) Extensión y designación específica del material}

Registrar la cantidad de unidades físicas: se deberá indicar el número de mapas completos o el número de pliegos, en caso de que el mapa esté impreso en dos o más segmentos ubicados en hojas separadas, se consignará, por ejemplo, "1 mapa en dos hojas". Puede también ocurrir que dos o más mapas se encuentren impresos en un solo pliego, en ese caso se asentará, por ejemplo, "3 mapas en una hoja".

\section{b) Disposición}

Es necesario describir toda disposición inusual de los mapas en los pliegos. Las AACR2 indican que, si el mapa se continúa en la otra cara del pliego con la misma escala, se use para describirlos la expresión "ambas caras". En caso de que el mismo mapa se presente en cada una de las caras con los rótulos en diferente lengua, las reglas prescriben el uso de la forma "reverso con reverso".

\section{c) Método de producción}

Hasta la segunda mitad del siglo XV se requerían materiales valiosos y un gran esfuerzo por parte de artífices muy especializados para elaborar un documento cartográfico. Por esta razón fue limitada la producción de manuscritos, que circulaban en ámbitos reducidos.

La aplicación a la cartografía de sistemas mecánicos de reproducción, produjo un gran aumento del número de ejemplares a un costo más reducido, situación que favoreció la accesibilidad y divulgación de los mapas.

Durante más de tres siglos, el grabado en relieve (madera), y en hueco, (metal) predominaron en la cartografía impresa. Para la técnica de grabar en relieve se tallaba con instrumentos cortantes una matriz de madera, dejando en realce los elementos de la imagen (líneas, puntos, letras). La superficie en relieve se entintaba y la imagen se trasladaba al papel aplicando presión con una prensa. ${ }^{6}$
6. Un pequeño diagrama que representa un mapamundi de "T en O" incluido en las etimologías de San Isidoro de Sevilla, estampado con la técnica de la xilografía por Günter Zainer en Augsburgo en 1472, se considera el primer mapa impreso en Europa. 
La técnica de grabado en madera (xilografía) no era la más adecuada para la reproducción de las líneas y los detalles finos, propios de la representación territorial. Por esta razón a partir del último tercio del siglo XVI el grabado en metal pasó a ser el método más empleado para los documentos cartográficos.

En el grabado en hueco sobre metal o calcográfico, la imagen se delineaba tallando surcos sobre una lámina metálica pulida. La tinta se aplicaba cuidadosamente en esos surcos, se aplicaba la lámina de metal sobre el papel húmedo y bajo la presión de una prensa especial denominada tórculo, se reproducía la imagen. ${ }^{7}$

Tres siglos más tarde, en 1796, Alois Senefelder creó un nuevo sistema de reproducción de imágenes: la litografía. Este método se basa en el trazado de la imagen con tintas grasas aplicadas con pluma y pincel sobre la superficie de una piedra calcárea muy pulida. La piedra se humedece y se entinta, también con una tinta grasa. La tinta solo permanece donde se encuentran las líneas del dibujo, debido a que la grasa atrae a la grasa y el agua la rechaza. Después se presiona sobre un papel con una prensa litográfica y se obtiene una imagen de gran calidad. Las ventajas de esta técnica - menor exigencia de mano de obra, economía de tiempo, reutilización de la piedra y posibilidad de largas tiradas - hicieron que, a partir de la década de 1820, la litografía se convirtiera en el principal medio para la reproducción de mapas. $^{8}$

A partir de 1830, comenzó a utilizarse la cromolitografía, estampación en varias tintas que se aplicó primero en tonos separados y luego de manera superpuesta. Este sistema permitió que se ampliara la capacidad informativa de los mapas, en los que se pudieron incluir claves cromáticas para identificar distintos elementos representados en el documento.

\section{d) Color}

Desde las primeras producciones cartográficas se procuró agregar color a las imágenes monocromas de los grabados. En las xilografías solía aplicarse la impresión superpuesta de planchas de madera con distintos tonos, los más comunes negro y rojo.

La práctica más frecuente fue la iluminación de los grabados a pincel. En un principio se siguió el estilo de las miniaturas medievales: densas masas de color sobre grandes superficies que daban a la estampa la apariencia de una pintura y ocultaban parte del trazado. A fines del siglo XVI se impuso la técnica del coloreado a base de aguadas que se denomina lavado. Para el lavado se emplean colorantes y pigmentos de gran transparencia y paletas con mayor número de matices.

Los colores representados con mayor frecuencia en los documentos cartográficos son: verde, amarillo, carmín, rojo, negro, azul y marrón. Cada artesano tenía su propia escala cromática, aunque, como los mapas son un sistema de transmisión de información, existía un código común para el uso de algunos colores en la representación de determinados elementos como el mar, el cielo y las montañas. A fines del siglo XVIII aparecieron las primeras clasificaciones de colores, que permitieron que cada tonalidad pudiera ser definida sin ningún tipo de confusión.

El color es un componente fundamental de la cartografía histórica porque, más allá de su valor estético, cumple una función simbólica, mimética y convencional (San Antonio Gómez, Asenjo Villar y Velilla Lucini, 2008).
7. En 1477 se empleó por primera vez la calcografía para la impresión de un documento cartográfico: el grabador Domenico de Lapis publicó en Bolonia la Cosmographia de Ptolomeo con 26 mapas impresos mediante planchas de cobre.

8. En el Manual del soldado español en Alemania del español Carlos Gimbernat, publicado en Munich en 1807 , se incluyó por primera vez un mapa impreso mediante el procedimiento litográfico.

9. El primer manual sobre el lavado aplicado a los dibujos arquitectónicos, que se utilizó también en cartografía, fue L'art de laver, ou nouvelle manière de peindre sur le papier suivant le coloris des desseins qu'on envoye àla Cour, publicado en Lyon en 1687 por el Ingeniero e Inspector general de Puentes y Carreteras H. Gautier de Nismes. Su autor describe ampliamente los pigmentos, a los que clasificó en función de su color y de los aglutinantes y procedimientos empleados para obtener los diferentes matices. 


\section{e) Medio}

La tinta utilizada en los grabados era similar a la de la imprenta. Existía una amplia variedad de recetas para las tintas, que eran de base grasa. Se utilizaban en su composición, aceites (de nuez, de linaza, etc.), pigmentos (negros "de humo", "de viñas") $\mathrm{y}$ aditivos naturales.

\section{f) Material}

En Occidente, los soportes históricos de mapas y planos fueron el pergamino, la tela y el papel. Los dos primeros corresponden a técnicas manuales, mientras que sobre el papel se desarrollaron las formas de reproducción que se iniciaron con el grabado.

La estampación se efectuaba sobre papel fabricado a mano a partir de fibras textiles (algodón, lino, cáñamo). La estructura de la forma utilizada para la fabricación manual deja en el papel una huella denominada verjura. En muchos casos estos papeles presentan además una marca de agua y, a veces, una contramarca, del fabricante o de la institución para la que se producía, denominada filigrana.

En la segunda mitad del siglo XVIII se comenzó a utilizar para el grabado de mapas, el papel vitela o avitelado, de textura más homogénea. Desde comienzos del siglo XIX se empleó el papel continuo o de fabricación industrial. A mediados de ese siglo se introdujeron fibras de madera en la pasta papelera. Esas fibras, a causa de la lignina que contienen, ocasionan un alto deterioro del soporte.

\section{g) Dimensiones}

Para los documentos cartográficos antiguos, las AACR2 indican registrar las dimensiones hasta el milímetro más cercano. En los mapas antiguos es importante consignar el alto y el ancho de la imagen grabada y también del tamaño total del pliego que incluye los márgenes.

\section{Notas}

Las notas cobran gran importancia en la descripción del documento cartográfico antiguo porque en ellas se consignan, en forma precisa y breve, las características internas y externas más relevantes del material.

La exhaustividad de las notas dependerá de las necesidades de información de los usuarios de la biblioteca que alberga los documentos. En general, la tipología de los usuarios de este material suele ser muy amplia, así como sus demandas informativas. Esto implica un análisis crítico del mapa antiguo que permita generar notas de utilidad para investigadores de diferentes disciplinas: historia, geografía, arte, diseño, semiología, bibliografía, etc.

Para la elaboración de las notas se recomienda adoptar una fórmula de entrada para cada tipo y utilizar una terminología homogénea (Jiménez Pelayo, 1996:142).

\section{a) Naturaleza y alcance de la obra}

En muchos casos el título del mapa no es lo suficientemente elocuente o, por el contrario, es más amplio que lo verdaderamente representado. También puede ocurrir que esté expresado en otra lengua. En estos casos en la nota se indicará el territorio o los territorios que abarca. 
Si un documento incluye varios mapas y se ha catalogado en conjunto, se redactará una nota de Contiene.... En la que se consignará el título de cada mapa, mención de responsabilidad (si es diferente de la del conjunto) y datos matemáticos.

\section{b) Lengua del documento}

Hasta el siglo XVII era muy frecuente el uso del latín para los textos incluidos en los documentos cartográficos. En algunos casos se alternaban datos en lengua vernácula con otros en latín. Es importante indicar la lengua empleada en la cartela, la toponimia, las leyendas, las escalas y los textos expositivo-explicativos contenidos

\section{c) Variantes del título}

Los mapas antiguos pueden presentar más de un título o estar representados con variantes en algunos catálogos. Es conveniente registrar todas las formas.

\section{d) Títulos paralelos. Dedicatorias y otras presentaciones}

Este tipo de documentos suele contener títulos paralelos, dedicatorias, lemas, etc., que aportan información muy valiosa y por lo tanto deben indicarse en las notas.

\section{e) Mención de responsabilidad}

En estas notas se pueden indicar las menciones de responsabilidad que no aparecen en el documento y que se han tomado de diferentes fuentes, que deben citarse. Se pueden incluir seudónimos, variaciones de nombre y nombres desarrollados. También se pueden mencionar los trabajos atribuidos, indicando a quien se atribuye la autoría del documento, por quien es atribuida y en qué obra o artículo se menciona.

\section{f) Edición e historia bibliográfica}

Datos sobre la relación del documento cartográfico con otros documentos, por ejemplo: otras ediciones, obras a las que había pertenecido originalmente, etc.

\section{g) Detalles matemáticos: meridiano de origen, orientación}

\section{Meridiano de origen}

Durante siglos, los astrónomos y geógrafos determinaron diferentes meridianos de origen según la época en que les tocó vivir o su país de procedencia.

A principios de la Edad Moderna el Tratado de Tordesillas (1494) puso fin los conflictos entre España y Portugal por el límite de sus zonas de expansión en el Atlántico. La nueva línea de demarcación, que pasaba a 370 leguas al Oeste de las Islas de Cabo Verde, fue utilizada como verdadero meridiano cero. En el siglo XVI, Mercator estableció el uso del primer meridiano, el de las islas Azores.

En 1634 en el congreso de matemáticos y astrónomos celebrado en Paris y presidido por el rey Luis XIII de Francia, se determinó que el meridiano de referencia pasara por el extremo más occidental de la isla de El Hierro (cabo de Orchilla), la más occidental y meridional de las Islas Canarias. El meridiano de la isla de El Hierro, fue aceptado por todos los países cristianos, excepto por los holandeses que fijaron el meridiano de origen en el que pasa por el volcán Teide, isla de Tenerife (Islas Canarias). 
10. Para las denominaciones de los vientos incluidos en la Rosa Náutica se puede consultar la tabla incluida en: Posada Simeón, José Carlos (2010: 15-16).

11. El rumbo es un concepto propio de la navegación, indica una trayectoria, por ejemplo, si un barco se dirige hacia el sur se dice que su rumbo es Norte-Sur. En los mapas, el rumbo se representa mediante una línea con dos extremos: el punto de donde procede y aquel hacia donde se dirige. En la navegación de cabotaje, el piloto identificaba sobre la carta el punto de partida y el de arribo y buscaba la línea que los uniese. Si coincidía con una de las líneas de rumbo, esa era la que debía seguir. Si no encontraba una línea de rumbo que pasase por ambos puntos, trazaba una línea recta que los uniese y llevaba esa dirección hasta la Rosa Náutica para adoptar la paralela más cercana.
A partir de 1675, los británicos fijaron el meridiano de origen en el Observatorio Real de Greenwich. Este pronto fue el más utilizado en las cartas náuticas de todo el mundo. Pero algunos países mantuvieron en su cartografía, los meridianos de sus observatorios de referencia, como es el caso de España que en la segunda mitad del siglo XVIII lo ubicó en Cádiz, donde se había fundado el Real Observatorio de la Marina en 1753.

En 1884 se llevó a cabo en Washington, Estados Unidos de América, la Conferencia Internacional para la adopción del Primer Meridiano Internacional, durante la cual se acordó establecer el Meridiano de Greenwich como Meridiano Magistral de Longitudes. A partir del Meridiano de Greenwich la longitud se contaría en dos direcciones de $0^{\circ}$ a $180^{\circ}$, la longitud este, positiva, y la oeste, negativa. También se decidió que el Día Universal comenzara a partir de la media noche del Primer Meridiano, dividiéndose su duración en 24 horas, que darían lugar al sistema de los husos horarios. Pese al acuerdo, no todos los países adhirieron a este sistema, muchos lo hicieron recién durante el transcurso del siglo XX.

\section{Orientación}

En las cartas de navegar o cartas portulanas comienza a utilizarse la Estrella de los Vientos, también llamada Rosa Náutica o Rosa de los Vientos, como forma para simbolizar la orientación. La Rosa Náutica primitiva representaba los cuatro vientos principales que se correspondían con los cuatro puntos cardinales y en latín se denominaban: Septentrión, Oriente, Meridie o Austro y Occidente.

Por las exigencias de la navegación, la primera división en cuatro vientos cardinales se subdividió sucesivamente en mitades. Hacia el siglo XIII a cada uno de los cuatro vientos se agregaron primero cuatro vientos intermedios (nordeste, sudeste, sudoeste y noroeste) que junto con los anteriores formaron los ocho vientos enteros. Posteriormente la Rosa Náutica quedó dividida en doce vientos al sumar a cada viento principal, dos vientos llamados colaterales. En el siglo XIV la Rosa de los Vientos aparece compuesta por 32 vientos. Para la denominación de los vientos o puntos cardinales, cada nación y cada cartógrafo adoptaba tanto vocablos como iniciales en latín, en griego o en lengua vernácula. ${ }^{10}$

En estas cartas, las líneas de rumbos, formadas por la prolongación de los ángulos de una Rosa de los Vientos central, que se entrecruzan con las de otras Rosas secundarias, formaban una tupida trama de múltiples direcciones. ${ }^{11}$

En los mapas antiguos, herederos de las cartas portulanas, la Estrella de los Vientos central aparece integrada en la red de rumbos, señalando el norte. En las primeras cartas, el norte se simbolizaba en la Estrella con la punta de una lanza, posteriormente se incluyó, debajo de la lanza, la letra "T" de Tramontana, uno de los nombres que recibía ese punto cardinal. Más tarde se señaló solo mediante esa inicial y a partir del Renacimiento esa representación se reemplazó por la flor de lis. El Levante (este), hasta fines del siglo XVI, se marcaba en la Estrella con una cruz griega.

\section{h) Publicación, distribución}

Detalles sobre la impresión, publicación, distribución que puedan ser de interés para su identificación.

\section{i) Rotulación}

La rotulación cartográfica es el conjunto de nombres, genéricos y propios (topónimos) y de números que se incluyen en un mapa. 
Aun cuando las relaciones que mantenían los diferentes centros de producción cartográfica entre los siglos XVI y XVIII, provocaron un intercambio frecuente de estilos caligráficos, la rotulación constituye una importante fuente de identificación de autorías y fechas. Su relación con otros elementos cartográficos como el color, la simbología y la ornamentación, entre otros, permiten aproximarse al contexto de producción de un mapa y en principio, ubicar al mismo en una zona y en un siglo determinado. En los mapas antiguos, la toponimia se rotulaba perpendicularmente a la línea de la costa lo que facilitaba su lectura seguida girando el mapa.

\section{j) Notas explicativas, comentarios}

Advertencias de los autores o editores, notas descriptivas o explicativas al verso, etc. Desde el punto de vista cartográfico, existen tres elementos naturales, característicos de todo espacio geográfico, que se han representado de variadas formas: las cadenas montañosas o picos aislados, los ríos y la vegetación.

\section{k) Relieve}

Para dar al plano un efecto plástico que permita percibir de manera inmediata las formas del relieve, la cartografía recurre a distintas formas de representación. El procedimiento cartográfico más antiguo que se empleó para simbolizar el relieve fue el de alzado o perfiles abatidos. Este método consiste en el dibujo de figuras convencionales, simulando perspectivas superpuestas tomadas desde un punto. Las montañas se dibujaban como vistas hacia arriba desde el valle. Este recurso gráfico aparece en los primitivos mapas de Babilonia, como el de Ga Sur del siglo XXV a C., y se aplicó hasta finales del siglo XVII.

En menor medida y de forma muy heterogénea, se usó el sombreado. En los mapas dibujados en perspectiva, se representaba la luz incidiendo en las montañas y la sombra correspondiente, esto producía la percepción de relieve de las mismas. En los mapas iluminados en colores a la acuarela, el efecto de las sombras se conseguía mediante manchas de color más o menos oscuras según la orientación y la pendiente estimada de las laderas.

Otra técnica empleada, aunque de manera menos frecuente, fue la perspectiva paralela o caballera. En este caso la profundidad se indica a través de líneas oblicuas respecto a las horizontales y verticales del plano frontal, que sigue siendo el principal.

Otras formas utilizadas hasta el siglo XIX para representar en el plano el relieve del terreno son: las vistas a vuelo de pájaro, los puntos acotados, las líneas estructurales, las líneas de máxima pendiente, las curvas de configuración horizontal, las curvas de nivel y las normales.

\section{I) Datos hidrográficos}

El mar se iluminaba en tonos azules y verde claro. Las olas sobre las costas se representaban con tonos más intensos del color elegido. Para las playas se empleaba un punteado en color gris o negro.

Los ríos se dibujaban mediante una línea continua. Los más importantes se simbolizaban a través de una doble línea. Por regla general se trazaban desde su nacimiento, en montañas o lagos, hasta su desembocadura, pero en muchas ocasiones por el desconocimiento del interior de los territorios, se delineaban solo los cursos finales. En la representación de los lagos se empleaban diversos tonos de azul. 


\section{m) Vegetación}

Los árboles individuales se representaban con perfiles abatidos. Para la caracterización de bosques se siguió usando el recurso de árboles individuales en perfil abatido con un sombreado del espacio entre ellos.

\section{n) Representación de ciudades}

La representación de la planta de las ciudades en proyección ortogonal es el recurso gráfico más utilizado y se remonta a las primeras civilizaciones. También es muy frecuente en cartografía el dibujo de ciudades "a vista de vuelo de pájaro". Otros recursos gráficos empleados para representar ciudades han sido la perspectiva caballera, la isométrica y la lineal.

\section{ñ) Elementos decorativos e iconografía}

Desde sus inicios la cartografía estuvo vinculada a representaciones artísticas y simbólicas. En Europa a partir del siglo XIII aumentó el número de elementos decorativos en los mapas. Los mapamundi aparecían profusamente decorados, al simbolismo cristiano se agregaron paisajes, retratos de personas ilustres de la época y elementos históricos mezclados con representaciones de mitos medievales.

En las primeras cartas náuticas manuscritas los asentamientos costeros se marcaban solo con su nombre y se utilizaba color únicamente en el trazado de la red de líneas de rumbos y en las rosas de los vientos, pero a partir del siglo XVI se comenzaron a añadir motivos artísticos.

Desde fines del siglo XV, los adelantos en la navegación, los viajes de descubrimiento y exploración, la generalización del uso de la imprenta y las nuevas técnicas de grabado de imágenes dieron un enorme impulso a la cartografía.

En los mapas impresos se incorporaron diversos elementos simbólicos, formas ornamentales y motivos ilustrativos coloreados: banderas y escudos de armas de las autoridades que gobernaban los territorios representados, retratos de gobernantes, de aristócratas o de militares destacados, vistas a vuelo de pájaro de las principales ciudades, buques que surcaban el mar con su velamen desplegado, escenas con animales exóticos de las zonas remotas del mundo, herramientas de los oficios vinculados con la navegación (compases, cuadrantes, astrolabios, etc.).

Para esta época, aparecieron en los documentos cartográficos los elementos formales: marcos exteriores y cartelas (estas últimas inspiradas en las que se usaban durante el siglo XV en la arquitectura, pintura, escultura y orfebrería italiana de inspiración clásica). Las cartelas se usaban para resaltar los títulos de los mapas y los contenidos textuales más importantes -dedicatoria, responsable, lugar y año de publicación-y servían para que los grabadores demostraran sus habilidades artísticas (Albardonedo Freire, 2010: 9). Adquirieron tal importancia que fueron recopiladas en repertorios italianos, flamencos y holandeses destinados al uso de arquitectos, escultores, grabadores, cartógrafos e impresores.

La ornamentación incluyó personajes mitológicos, instrumentos cartográficos o herramientas (que solían enmarcar el gráfico de la escala), escudo de armas de la personalidad a la que se dedicaba el mapa, escenas características de las diversas regiones que incluían actividades agrícolas, ocupaciones, trajes típicos, costumbres de sus habitantes, etc. 
Los mapamundi mostraban un extenso repertorio de imágenes decorativas: ilustraciones antropomórficas de los vientos principales; figuras simbólicas que representaban los continentes, los doce meses del año o las cuatro estaciones; retratos de cartógrafos destacados; indumentaria de culturas exóticas; maravillas del mundo antiguo e imágenes alegóricas de los ríos, entre otras.

A partir de la llegada de los europeos al continente americano, con el propósito de dar a conocer las particularidades de las nuevas tierras descubiertas, se incorporaron a los mapas imágenes de su flora y su fauna y de los nativos que la poblaban. Pero en muchos casos, en los mapas de América, tanto las figuras humanas como las imágenes de animales van a presentar características más imaginarias que reales.

Los animales monstruosos, producto de la imaginación medieval, se trasladaron al extraño mundo americano recién descubierto. Para describir la exótica fauna del nuevo continente (pingüinos, llamas, aves multicolores, ballenas, etc.), los europeos recurrieron a las características físicas de animales conocidos por ellos y armaron imágenes que mezclaban elementos reales y fabulosos. De esta manera los seres fantásticos, marinos y terrestres, pasaron a formar parte del imaginario gráfico de los grabadores e impresores de la época.

Son muchos los autores que coinciden en asegurar que esa "cartografía de lo imaginario", esa representación de una tierra poblada por monstruos antropomorfos o zoomorfos, por nativos gigantes y sanguinarios, por amazonas, hombres acéfalos, y caníbales sirvió para justificar la permanencia del europeo en tierras americanas y legitimar el uso que hizo de la coerción y de la fuerza. ${ }^{12,13}$

\section{o) Documento vinculante}

Es necesario, especialmente en los mapas en hoja suelta, indicar datos que figuren en el mismo documento o en obras de referencia, sobre la pertenencia a una obra mayor.

\section{p) Conservación}

Los mapas y planos plantean serios problemas de conservación en bibliotecas y archivos, por su tamaño, por la fragilidad de sus soportes y por la variedad de formatos. Además del almacenamiento inadecuado, el principal factor de deterioro de este tipo de documentos es la manipulación.

Es de gran importancia registrar el estado de conservación del material cartográfico, para decidir sobre las condiciones de acceso al mismo por parte de los usuarios, sobre las medidas a tomar ante una eventual exposición y sobre el sistema de reproducción más adecuado para su preservación.

\section{A modo de conclusión}

Este artículo describe someramente algunas de las características, propias de documentos tan particulares como son los mapas antiguos. Está dirigido a los bibliotecarios de instituciones que no cuentan con recursos técnicos ni económicos para efectuar el procesamiento documental de este material tan complejo. Probablemente no son muchas las bibliotecas de este tipo que tienen en su colección mapas anteriores a 1901. Los comentarios incluidos en cada área y en las notas, procuran brindar alguna ayuda, no solo para la descripción de los mapas, sino también para identificar el lugar, la época y los métodos de elaboración de estos materiales, con el fin de completar datos, muchas veces difíciles de hallar en los mismos documentos.
12. “... el "mito cartográfico" se presenta como el justificador de la acción conquistadora, colonizadora y evangelizadora, pues ¿qué hacer con una tierra cuyos habitantes aparecen confundidos con la mismísima revitalización del mito clásico de las amazonas y la vivificación de toda una generación de monstruos antropomorfos o zoomorfos de raigambre europea o emergidas del imaginario nativo como el ser mitológico vinculado a las profundidades de las aguas enemigo de los pescadores: el Ipupiara? Se hacía urgente, entonces, la salvación de estos pueblos y, a la postre, la presencia de la metrópoli en el Nuevo Mundo." (Ortega Sánchez, 2013: 5)

13. “...los europeos construyen una imagen de seres gigantescos y monstruosos en un espacio lejano, extraño y desconocido, bajo lo cual legitiman sus acciones de conquista y al mismo tiempo definen su propia identidad en oposición a este mundo insólito y extraordinario." (Castro Hernández, 2012: 43). 
Un recurso recomendable para obtener información sobre estas obras, es la consulta de colecciones digitales de mapas antiguos. No es tarea sencilla encontrar la imagen digital de este tipo de documento. Con frecuencia, al buscar un mapa aparecen en pantalla "siluetas geográficas" similares a la del documento en soporte papel con el que se quiere comparar. Pero cuando se observan con detenimiento los detalles, se advierte que se trata de un mapa distinto. Esto se debe a que a menudo las planchas de grabado se vendían y eran utilizadas, con menor o mayor número de modificaciones, en numerosas ediciones, preparadas por diferentes talleres de impresión. Cuando se logra localizar una imagen idéntica a la del ejemplar que se encuentra en la colección propia, generalmente también se pueden obtener datos valiosos registrados por el organismo que ha digitalizado el mapa.

La mejor forma de difundir y preservar este tipo de obras es la digitalización. Pero no todas las instituciones están hoy en condiciones de acceder a esa forma de reproducción. Es conveniente, entonces, incluir en el registro catalográfico, un enlace directo a la imagen del mapa encontrada en la colección digital de alguna otra unidad de información, de ese modo se facilitará la consulta por parte del usuario y, al mismo tiempo, se evitará la excesiva manipulación del documento original.

Existen experiencias de instituciones que con escasos recursos económicos han logrado realizar un interesante trabajo para preservar y difundir fondos cartográficos, como es el caso de la Biblioteca Histórica Digital de Extremadura. Esta unidad de información reúne documentos cartográficos en formato digital, anteriores a 1901, que representan el territorio extremeño. La cartoteca se publica en la Web desde 2011 y solo dos personas se ocupan de las tareas: una Licenciada en Documentación y un Licenciado en Geodesia y Cartografía con conocimientos profesionales de fotografía. Utilizan ISBD (CM) para la catalogación, que se traduce a los formatos MARC e ISO 19115 que define el modelo de metadatos para describir información geográfica. La información puede ser consultada en esos tres formatos (González Suárez, 2016).

En este artículo, también se ha recomendado para la descripción catalográfica del material cartográfico antiguo, la aplicación de las normas ISBD (CM) y AACR2, pese a que ya muchas unidades de información, en diferentes partes del mundo, las han reemplazado, o tienen previsto hacerlo a corto plazo, por el estándar de metadatos RDA. Esta decisión de emplear esos códigos catalográficos tradicionales, que puede ser cuestionada, obedece a varios motivos que explicaré a continuación:

En el artículo " $R D A$, el nuevo código de catalogación: cambios y desafios para su aplicación", sus autoras señalan que las RDA no parecen simplificar la catalogación y por lo tanto tendrían que ser utilizadas por catalogadores expertos (Picco y Ortiz Repiso, 2012). Siete años más tarde, deberíamos plantearnos si en Argentina se ha capacitado adecuadamente a los bibliotecarios para la implementación de las RDA. También podríamos preguntarnos si los alumnos de las escuelas de Bibliotecología, universitarias y terciarias, han sido formados para trabajar de manera apropiada con estas directrices. ¿Cuántas promociones cuentan con la preparación que exige RDA?

Por otra parte, existen en la Argentina, bibliotecas con importantes colecciones de mapas antiguos que ni siquiera cuentan con un catálogo en línea. A veces, solo disponen de catálogos impresos, con registros que contienen escasos datos, que han subido en forma de documento XML a la página Web de la institución

Por último, resulta importante señalar que la Biblioteca Nacional de España, que en diciembre de 2014 había suspendido la implementación del estándar RDA, comenzó a 
aplicarlo, desde principios de 2019, para crear registros. Pero lo hará de acuerdo a un cronograma que, en principio, solo incluye las monografías modernas. El resto de los materiales que componen su fondo documental, se incorporará en los próximos años.

Las RDA significan un cambio que indudablemente es necesario y que se afianzará en los próximos años, pero cuando aún falta tanto por hacer en nuestro país, en relación a esas directrices ¿deberíamos comenzar a aplicarlas en los documentos cartográficos antiguos? 


\section{Q Referencias Bibliográficas}

"AACR2. Reglas de Catalogación Angloamericanas - 2ª ${ }^{\underline{a}}$. Ed., revisión de 2002, actualización de 2003. (2004). Bogotá, D.C.: Rojas Eberhard.

» Albardonedo Freire, Antonio J. 2010. La creación artística en la cartografía. En Posada Simeón, J.C. y P. Peñalver Gómez, coords. Cartografía histórica en la Universidad de Sevilla, Universidad de Sevilla. p. 104-119. <http://expobus.us.es/ cartografia/index.html> [Consulta: 6 octubre 2014].

"Carrascal Simón, Andreu y Rosa María Gil Tort. 2007. Los documentos de Arquitectura y Cartografía. Qué son y cómo se tratan. Gijón: Trea.

"Castro Hernández, Pablo. 2012. Monstruos, rarezas y maravillas en el Nuevo Mundo. Una lectura a la visión europea de los indios de la Patagonia y Tierra del Fuego mediante la cartografía de los siglos XVI y XVII. En Revista Sans Soleil - Estudios de la Imagen. No. 4. <http://revista-sanssoleil.com/ wp-content/uploads/2012/o2/art-Pablo-Castro.pdf> [Consulta: 7 septiembre 2014].

»Funes, Graciela. 2014. Una muestra de la mapoteca Manuel Selva. América del Sur en la cartografía francesa el siglo XVIII. Muestra realizada en Biblioteca Nacional Argentina, Buenos Aires, agosto-septiembre 2014.

»Galera i Monegal, Montserrat. 2001. La cartoteca: estructura, organización y uso. En Monteagudo López Menchero, J. y J. Himénez Pelayo, coords. La documentación cartográfica: tratamiento, gestión y uso. Huelva: Universidad de Huelva. p. 487-526.

" García Ruipérez, Mariano. 2010. La descripción de documentos cartográficos: estado de la cuestión. En Códices. Vol. 6, no. 2, 195-208. <http://eprints. rclis.org/20217/1/La\%2odescripci\%C3\%B3n\%2ode\%2odocumentos\%20 cartogr\%C3\%A1ficos_estado\%2ode\%2ola\%2ocuesti\%C3\%B3n.pdf > [Consulta: 4 abril 2015].

»González Suárez, Beatriz. 2016. La cartoteca histórica digital de Extremadura o como dar contenido a un recurso con presupuesto cero. En Revista Catalana de Geografía. Vol. XXI, no. 54. <http://www.rcg.cat/articles.php?id=368> [Consulta: 20 marzo 2019].

"Gorostiaga, Juan Pablo y Silvia María Mateo-Ré. 2008. Descripción de material cartográfico: una experiencia compartida. En I Encuentro Nacional de Catalogadores. (noviembre de 2008: Buenos Aires). Trabajo presentado. Buenos Aires: Biblioteca Nacional. <http://www.bn.gov.ar/descargas/catalogadores/ ponencia_gorostiaga_mateo_re.pdf > [Consulta: 9 abril 2015].

"Harley, John Brian. 2005. La nueva naturaleza de los mapas: ensayos sobre historia de la cartografía. México: Fondo de Cultura Económica.

»Hazrum, Flavio Augusto. 2008. Materiales cartográficos: catalogación y análisis temático. En I Encuentro Nacional de Catalogadores. (noviembre de 2008: Buenos Aires). Trabajo presentado. Buenos Aires: Biblioteca Nacional. <http:// www.bn.gov.ar/descargas/catalogadores/ponencia_hazrum.pdf> [consulta: 9 de abril de 2015].

"International Federations of Library Associations and Institutions. 1987. International Standard Bibliographic Description for Cartographic Materials (ISBD- 
CM). <http://www.ifla.org/files/assets/cataloguing/isbd/isbd-cm_1987.pdf> [Consulta: 13 abril 2015].

"International Federations of Library Associations and Institutions. 2013. Descripción Bibliográfica Internacional Normalizada. Edición consolidada. <http:// www.ifla.org/files/assets/hq/publications/series/44-es.pdf > [Consulta: 13 abril 2015].

» Jiménez Pelayo, Jesús J. 1996. La descripción documental del fondo cartográfico antiguo: análisis de los aspectos conflictivos. En Revista Española de Documentación Científica. Vol. 19, no. 2, 131-149. < http://redc.revistas.csic.es/ index.php/redc/article/view/621/696 > [Consulta: 15 mayo 2015].

"Líter Mayayo, Carmen. 2007. Tesoros cartográficos de la Biblioteca Nacional de España. En Anales de mecánica y electricidad. Vol. 84, no. 3, 51-61. <https:// www.icai.es/contenidos/publicaciones/anales_get.php?id=1433> [Consulta: 15 mayo 2015].

"Líter Mayayo, Carmen. 2011. El tratamiento catalográfico de los mapas en las bibliotecas. En Revista ph. No.77, 24-25.

" Líter Mayayo, Carmen y Carmen García Calatayud. 1999. Materiales cartográficos: Manual de catalogación. Madrid: Arco Libros.

"Lois, Carla Mariana. 200o. La elocuencia de los mapas: un enfoque semiológico para el análisis de cartografías. En Documents d'Anàlisi Geogràfica. No.36, 93-109. <http://ddd.uab.es/pub/dag/o2121573n36p93.pdf> [Consulta: 13 abril 2015].

"Lois, Carla Mariana. 2015. El mapa como metáfora o la espacialización del pensamiento. En Tierra Brasilis. Vol. 2. <http://journals.openedition.org/terrabrasilis/1553> [Consulta: 18 junio 2018].

" Machado Lorenzo, Nancy. 2009. Propuesta metodológica para el procesamiento de los materiales cartográficos manuscritos, su validación en los mapas de los siglos XVII y XIX de la Biblioteca Nacional de Cuba José Martí. En Bibliotecas. Anales de Investigación. Vol. V, no. 5, 13-34. <http://anales. bnjm.cu/bundles/anales/dossiers/2009/nancy.pdf> [Consulta: 29 noviembre 2014].

" Ortega Sánchez, Delfín. 2013. Los caníbales de Antropófagos (Brasil) en la cartografía de los descubrimientos y los mitos geográficos: de la imagen cartográfica al imaginario del Brasil colonial. En Naveg@mérica. Revista electrónica de la Asociación Española de Americanistas. No.10. <http://revistas.um.es/navegamerica/issue/view/11701> [Consulta: 18 marzo 2015].

"Picco, Paola y Virginia Ortiz Repiso. 2012. RDA, el nuevo código de catalogación: cambios y desafíos para su aplicación. En Revista Española de Documentación Científica. Vol. 35, no 1, 145-173. < https://doi.org/10.3989/redc.2012.1.848 > [Consulta: 16 de mayo 2019].

"Posada Simeón, José Carlos. 2010. El tránsito de la cartografía medieval a la renacentista a través de la semiología cartográfica de los islarios de Da Li Sonetti, Bordone y Porcacchi. En Posada Simeón, J.C. y P. Peñalver Gómez, coords. Cartografía histórica en la Universidad de Sevilla, p.32-63. Sevilla: Universidad de Sevilla. <http://www.expobus.us.es/cartografia/salas/salao2/sozeooio1.pdf> [Consulta: 6 octubre 2014].

"RDA, resource description and access. 2010. American Library Association, Canadian Library Association, CILIP. 
"Sainz Guerra, Jaime. 2008. Los formatos de datos en la descripción cartográfica en archivos. En Revista Catalana de Geografía. IV Época, vol. XIII, no. 35. < http://www.rcg.cat/sendart.php?id=137> [consulta: 16 mayo 2019].

»San Antonio Gómez, Carlos de; Juan Carlos Asenjo Villar y Cristina Velilla Lucini. 2008. El color en la cartografía histórica. En Congreso Internacional de Ingeniería Gráfica. (20: junio de 2008: Valencia, España). Valencia: Universidad Politécnica de Valencia. <http://oa.upm.es/3514/1/INVE_MEM_2008_55286. pdf> [Consulta: 2 agosto 2014].

"Torricelli, Gian Paolo. 200o. El mapa. Imagen, modelo e instrumento: historia, teoría y aplicación en las ciencias sociales y económicas. Buenos Aires: Universidad de Buenos Aires. Facultad de Filosofía y Letras. Maestría en Políticas ambientales y territoriales. <http://www.gptorricelli.ch/index.php?Masterld=g1_26\&id_i tem $=26 \& \operatorname{lng}=1 \&$ node $=302 \&$ rif $=588 \mathrm{cf} 904 \mathrm{cf}>$ [Consulta: 29 septiembre 2014].

»Zumthor, Paul. 1994. La medida del mundo. Madrid. Cátedra. 


\section{Bibliografía consultada}

" Arenales de la Cruz, Reyes. 2009. Vientos, rumbos y direcciones en el horizonte. El nacimiento de una terminología científica en el Renacimiento. En Cuadernos del Instituto Historia de la Lengua. No. 3, 165-200. <https://www.cilengua.es/ sites/cilengua.es/files/book/5457/6cilengua-vientosrumbosydirecciones.pdf> [Consulta: 13 abril 2015].

»Bueno Jiménez, Alfredo. 2014. La representación gráfica de seres fabulosos en el «Nuevo Mundo" por el Taller de Bry. En Cuadernos de arte de la Universidad de Granada. No.41, 93-110. <http://revistaseug.ugr.es/index.php/caug/article/ view/1679/1870> [Consulta: 4 abril 2015].

"Chías Navarro, Pilar. 2008. La caligrafía de Mercator y otras singularidades de la rotulación de mapas. En EGA Revista de Expresión Gráfica Arquitectónica. No.13, 82-93. <http://oa.upm.es/2843/> [Consulta: 13 octubre 2014].

"Colomar Albájar, María Antonia. 2011. El tratamiento catalográfico diferenciado que recibe el mapa en los archivos. En Revista ph. No.77, 26-28. <http://www. iaph.es/revistaph/index.php/revistaph/article/view/3089/3089\#.VW9qKM9_ $\mathrm{NbM}>$ [Consulta: 26 mayo 2015].

»Crespo Sanz, Antonio y Alberto Fernández Wittembach. 2011. ¿Cartografía antigua o Cartografía histórica? En Estudios Geográficos. Vol. LXXII, no. 271, 403-420. <http://estudiosgeograficos.revistas.csic.es/index.php/estudiosgeograficos/ article/view/347/346> [Consulta: 26 julio 2014].

" García Rojas, Irma Beatriz. 2008. El estudio histórico de la cartografía. En Takwá Revista de Historia. Vol. 13, 11-32. <http://148.202.18.157/sitios/publicacionesite/ pperiod/takwa/Takwa13/irma_beatriz.pdf > [Consulta: 29 septiembre 2014].

" Gómez Gómez, Margarita. 2010. Libros con mapas y libros de mapas. Imprenta y cartografía en la Biblioteca de la Universidad de Sevilla. En Posada Simeón, J.C. y P. Peñalver Gómez, coords. Cartografía histórica en la Universidad de SeviIla, p. 188-211. Sevilla: Universidad de Sevilla. <http://www.expobus.us.es/cartografia/salas/sala1o/s1oeooio1.pdf > [Consulta: 6 octubre 2014].

»González González, Francisco José. 2011. La definición del Meridiano Cero en la cartografía histórica. En Revista ph. Vol. 77, 66-67. <http://www.iaph.es/revistaph/index.php/revistaph/article/view/3101/3101\#.VY1fr_I_NbM> [Consulta: 26 mayo 2015].

»Hermosín Miranda, Rocío. 2011. Características de los distintos soportes sobre los que se reproducen planos y esferas. En Revista ph. Vol. 77, 47-53. <http:// www.iaph.es/revistaph/index.php/revistaph/article/viewFile/3098/3098> [Consulta: 26 mayo 2015].

» Jiménez Martínez, María Jesús y Miriam Villar Cano. 2013. La cartografía entre los siglos XV y XVI, instrumentación y técnicas de levantamiento. Conferencia presentada en la Real Academia de Cultura Valenciana. Noviembre de 2013. Universidad Politécnica de Valencia. <http://www.fglorente.org/libros/Conferencia\%20Cartografia.pdf> [Consulta: 7 octubre 2014].

» Koeman, Cornelis y Marco van Egmond. 2007. Surveying and Official Mapping in the Low Countries, 1500-ca.1670. En The History of Cartography. 3 part, vol. 2, no. 43: Cartography in the Europear Renaissance, p.1246-1295. Chicago: University of Chicago. <http://www.press.uchicago.edu/books/HOC/HOC_V__Pt2/ 
HOC_VOLUME3_Part2_chapter43.pdf> [Consulta: 26 mayo 2015].

"Koeman, Cornelis; Günter Schilder; Marco van Egmond y Peter van der Krogt. 2007. Commercial Cartography and Map Production in the Low Countries, 1500-ca.1672. En The History of Cartography. 3 part, vol.2, no.44: Cartography in the Europear Renaissance, p.1296-1383. Chicago: University of Chicago. <http:// www.press.uchicago.edu/books/HOC/HOC_V3_Pt2/HOC_VOLUME3_Part2_ chapter44.pdf > [Consulta: 26 mayo 2015].

"Laborda Gil, Xavier. 1996. Cartografía barroca y retórica del discurso. En Revista Teoría/crítica. No. 3. <http://www.quadernsdigitals.net/datos/hemeroteca/r_56/ nr_623/a_8447/8447.pdf > [Consulta: 15 diciembre 2014].

» Líter Mayayo, Carmen; Ana Herrero Vigil y Francisca Sanchis Ballester. 1992. Geografia y cartografía renacentistas. Madrid: Akal.

» Machado Lorenzo, Nancy. 2011. El control de autoridades geográficas como instrumento para el desarrollo profesional de curadores de mapas en bibliotecas. En VII Encuentro Internacional y III Nacional de Catalogadores. Trabajo presentado. Buenos Aires: Biblioteca Nacional. <http://www.bn.gov.ar/descargas/ catalogadores/encuentro2011/ponencia-24-H-MachadoLorenzo.pdf> [Consulta: 9 abril 2015].

»Manso Porto, Carmen. 2011. La cartografía ptolemaica, precedente científico de la llegada a tierra firme. En Revista de Estudios Colombinos. No. 7, 7-25. <http:// www.rah.es/pdf/Cartografia_Ptolemaica_Precedente_llegada_Tierra_Firme_ Estudios_Colombinos_7_2011_.pdf > [Consulta: 27 agosto 2014].

" Martins Teixeira, Dante. 2008. A “América” de Jodocus Hondius (1563-1612): um studo das fontes iconográficas. En Revista do Instituto de Estudos Brasileiros. No. 46, 81-122. <http://www.ieb.usp.br/publicacoes/doc/rieb46_site_1322178255. pdf> [Consulta: 24 marzo 2015].

» Martins Teixeira, Dante (Curador). (2008). A Arte nos Mapas - Uma Viagem Pelos Quatro Cantos do Mundo. Exposición realizada en Casa Fiat de Cultura, Belo Horizonte, Minas Gerais (Brasil) entre el 12 de agosto y el 5 de octubre de 2008. <http://www.casafiat.com.br/wp-content/uploads/2014/o5/Clique-aquipara-baixar7.pdf> [Consulta: 4 abril 2015].

»Molina Mercado, Esperanza. 2009. Los mapas como recurso de información. En Anuario de Bibliotecología y Estudios de la Información. Vol. 1, 107-117. <http:// ru.ffyl.unam.mx:8080/jspui/bitstream/10391/781/1/o8_ABEI_Molina_107-117. pdf> [Consulta: 26 julio 2014].

»Olmedo Granados, Fernando. 2011. Evolución de las técnicas de reproducción de mapas. En Revista ph. No. 77, 20-23. <http://www.iaph.es/revistaph/index.php/ revistaph/article/view/3087/3087\#.VWZ7389_NbM> [Consulta: 26 mayo 2015].

"Porro Gutiérrez, Jesús María. 2004. Los tesoros de los mapas: la cartografía como fuente histórica (de la antigüedad a la época colombina). En Anales del Museo de América. Vol. 12, 53-80. < https://sede.educacion.gob.es/publiventa/ descarga.action?f_codigo_agc $=14353 \mathrm{C}>$ [Consulta: 2 agosto 2014].

»Raisz, Erwin. 1974. Cartografía. Barcelona: Omega.

»San Antonio Gómez, Carlos de. 2006. Metodología para el análisis gráfico de la cartografía histórica. En Congreso Internacional de Ingeniería Gráfica. (18: mayo-junio de 2006: Sitges, Cataluña). Trabajo presentado. Madrid: Universidad Politécnica de Madrid. <http://www.researchgate.net/publication/228829064_ Metodologa_para_el_anlisis_grfico_de_la_cartografa_histrica> [Consulta: 24 marzo 2015]. 
» Sánchez Martínez, Antonio. 2011. Representación por imitación: el renacimiento de la Geographia de Ptolomeo y las pinturas del mundo conocido. En Llull: Revista de la Sociedad Española de Historia de las Ciencias y de las Técnicas. Vol. 34, no. 74, 391-418. <http://dialnet.unirioja.es/revista/1511/V/34> [Consulta: 11 octubre 2014].

»Serrano Rivas, Andrés y Pedro Barbachano San Millán. 1987. Conservación y restauración de mapas y planos y sus reproducciones: un estudio RAMP. París: UNESCO. 
